\title{
Outcomes and costs of treating chronic obstructive pulmonary disease with inhaled fixed combinations: the Italian perspective of the PATHOS study
}

\author{
This article was published in the following Dove Press journal: \\ International Journal of COPD \\ 5 June 2014 \\ Number of times this article has been viewed
}

\author{
Alessandro Roggeri' \\ Claudio Micheletto ${ }^{2}$ \\ Daniela Paola Roggeri' \\ 'ProCure Solutions, Bergamo, Italy; \\ ${ }^{2}$ Respiratory Unit, Mater Salutis \\ Hospital, Legnago, Verona, Italy
}

\begin{abstract}
Purpose: Fixed-dose combinations of inhaled corticosteroids and long-acting $\beta 2$-agonists have proven to prevent and reduce chronic obstructive pulmonary disease (COPD) exacerbations. The aim of this analysis was to explore the clinical consequences and direct health care costs of applying the findings of the PATHOS (An Investigation of the Past 10 Years Health Care for Primary Care Patients with Chronic Obstructive Pulmonary Disease) study to the Italian context.

Patients and methods: Effectiveness data from the PATHOS study, a population-based, retrospective, observational registry study conducted in Sweden, in terms of reduction in COPD and pneumonia-related hospitalizations, were considered, in order to estimate the differences in resource consumption between patients treated with budesonide/formoterol and fluticasone/ salmeterol. The base case considers the average dosages of the two drugs reported in the PATHOS study and the actual public price in charges to the Italian National Health Service, while the difference in hospitalization rates reported in the PATHOS study was costed based on Italian real-world data.
\end{abstract}

Results: The PATHOS study demonstrated a significant reduction in COPD hospitalizations and pneumonia-related hospitalizations in patients treated with budesonide/formoterol versus fluticasone/salmeterol ( $-29.1 \%$ and $-42 \%$, respectively). In the base case, the treatment of a patient for 1 year with budesonide/formoterol led to a saving of $€ 499.90$ ( $€ 195.10$ for drugs, $€ 193.10$ for COPD hospitalizations, and $€ 111.70$ for pneumonia hospitalizations) corresponding to a $-27.6 \%$ difference compared with fluticasone/salmeterol treatment.

Conclusion: Treatment of COPD with budesonide/formoterol compared with fluticasone/ salmeterol could lead to a reduction in direct health care costs, with relevant improvement in clinical outcomes.

Keywords: disease management, pharmacoeconomics, direct health care costs, hospitalizations

\section{Introduction}

Chronic obstructive pulmonary disease (COPD) is a chronic respiratory disease characterized by a progressive and persistent airflow obstruction. The airflow limitation is usually progressive and associated with an abnormal inflammatory response of the lungs in response to noxious agents, including cigarette smoke, biomass fuels, and occupational agents. ${ }^{1,2}$

The prevalence of COPD has been estimated to range from $4 \%$ up to $20 \%$ in adults over 40 years of age, with a considerable increase by age, particularly among smokers. $^{3-7}$ In Italy, the estimates of prevalence for COPD from administrative database
Correspondence: Alessandro Roggeri

Via Camozzi I/C 24027 Nembro,

Bergamo, Italy

Tel +39035 52। I2I

Email alessandro.roggeri@

procuresolutions.it 
analysis range from $3.1 \%$ to $5.2 \%$, while a more recent Italian survey has estimated a prevalence ranging from $3.8 \%$ to $6.8 \% .^{8}$

The World Health Organization (WHO) suggested that COPD was the fourth largest cause of death in 2011, with three million deaths worldwide, representing $5.8 \%$ of total mortality. ${ }^{9}$ In Italy, out of the 37,659 deaths that occurred for respiratory diseases in 2008 (6.5\% of total mortality), 474 were related to asthma, whereas 20,786 (about 50\%) were associated with COPD (considering chronic bronchitis, emphysema and other chronic obstructive pulmonary disease). ${ }^{10}$

In 2005, COPD, was the tenth largest cause of total disability-adjusted life years (DALYs) lost worldwide, ${ }^{2}$ with 27,700 DALYs lost by 2020, COPD will only be preceded by ischemic heart disease, severe depression, traffic accidents, and cerebrovascular disease. ${ }^{11}$

The economic burden of COPD is considerable and will continue to grow as the number of elderly people continues to increase. ${ }^{12}$ The high impact of COPD on the Italian National Health Service (INHS) has been highlighted by several studies that demonstrate how patients with COPD incurred relevant costs in charges to the INHS, which increase with disease severity and presence of comorbidities. ${ }^{13-19}$ COPD also has a significant impact on INHS resource consumption in terms of hospitalizations: according to the last available annual report on hospitalizations of the Italian Ministry of Health (referring to year 2011), 58,930 hospitalizations for COPD were reported (10.2\% of the total hospital admissions for respiratory diseases), accounting for a total of 508,343 hospital days. ${ }^{20}$ In Italy, direct health care costs account for more than $70 \%$ of total disease costs, and the major cost drivers are repeated hospitalizations, access to emergency departments, and frequent recourse to general practitioner and specialist consultations. ${ }^{21}$

A fixed-dose combination of inhaled corticosteroids and long-acting $\beta 2$-agonists is the recommended treatment for the prevention of COPD exacerbations in severe patients. ${ }^{22-25}$

The present study was a cost consequences analysis that aimed to compare the major clinical outcomes (COPD hospitalizations and pneumonia-related hospitalizations) derived from the PATHOS (An Investigation of the Past 10 Years Health Care for Primary Care Patients with Chronic Obstructive Pulmonary Disease) study (clinical trial identifier NCT01146392; ClinicalTrials.gov) with direct health care costs related to treatment with budesonide/ formoterol or fluticasone/salmeterol for COPD, from the INHS perspective.
The cost consequences analysis estimates the costs as well as health consequences associated with one intervention compared with an alternative intervention for a health condition; here, the results, in terms of costs and health consequences, were presented separately.

\section{Material and methods Clinical outcomes and drugs dosages}

The PATHOS study was a retrospective, observational, population-based, matched-cohort, register linkage study of COPD patients conducted in Sweden, with a follow-up period of 11 years, comparing the effectiveness of the treatment of COPD patients with the budesonide/formoterol Turbuhaler ${ }^{\circledR}$ (AstraZeneca, Södertälje, Sweden) and fluticasone/salmeterol Diskus ${ }^{\circledR}$ (GlaxoSmithKline, Middlesex, UK; referred to as "budesonide/formoterol" and "fluticasone/salmeterol", respectively). Two matched cohorts, of 2,734 patients each, with similar characteristics were compared. The study design and main results of the PATHOS study have been already described elsewhere. ${ }^{26,27}$ In the PATHOS study, the treatment with budesonide/formoterol was more effective than fluticasone/salmeterol in preventing exacerbations and was associated with a significantly lower incidence rate of all clinical outcomes (Table 1). In summary, budesonide/formoterol reduced the annual rate of moderate to severe exacerbations by $26 \%$ compared with fluticasone/salmeterol $(P<0.0001){ }^{26}$ The significant and clinically relevant reduction in favor of budesonide/formoterol was apparent for all types of exacerbation event (eg, antibiotic use, oral steroid use, or hospital admission). Indeed, use of budesonide/formoterol reduced rates of COPD-related hospitalization by $29 \%(P<0.0001)$, with $34 \%$ fewer $(P<0.0001)$ hospital days due to COPD exacerbation compared with fluticasone/salmeterol. ${ }^{26}$ Moreover, the fluticasone/salmeterol group was associated with a $73 \%$ higher pneumonia rate $(P<0.001)$ and with $74 \%$ higher pneumoniarelated hospital admissions than was the budesonide/ formoterol group $(P<0.001)$. In the fluticasone/salmeterol group, 7.4 hospitalizations per 100 patient/years were reported compared with 4.3 hospitalizations per 100 patient/years in the budesonide/formoterol group. ${ }^{27}$ In the PATHOS study, COPDrelated hospitalizations were identified by the International Classification of Disease, 10th Revision Clinical Modification (ICD-10-CM) code of J44 as primary diagnosis or J44.0/J44.1 as secondary diagnosis; pneumonia was identified through the ICD-10-CM code J10-J18 (patients admitted to hospital because of pneumonia were distinguished from outpatient episodes of care). 


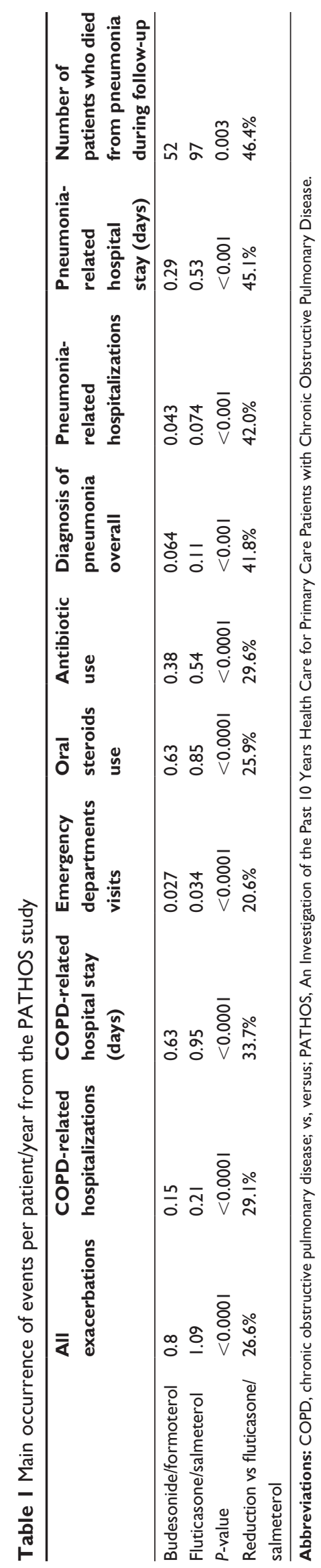

For the purposes of the current study, we included clinical outcomes with the higher potential economic burden for the INHS. Particularly, the PATHOS study revealed an intraclass difference between fixed-dose combination of inhaled corticosteroids and long-acting $\beta 2$-agonists in terms of COPD related hospitalizations (-29.1\% in the group treated with budesonide/formoterol versus [vs] fluticasone/salmeterol group) and of pneumonia related hospitalizations ( $-42 \%$ in the group treated with budesonide/formoterol vs fluticasone/salmeterol group). The mean collected dose over time reported in the PATHOS study for the two drugs was $568 \pm 235 \mu \mathrm{g} /$ day for budesonide/ formoterol (as budesonide dosage) and $783 \pm 338 \mu \mathrm{g} /$ day for fluticasone/salmeterol (as fluticasone dosage).

\section{Health care costs}

For this cost consequence analysis, yearly cost of the pharmacological treatment per group was estimated based on an INHS perspective; for these retail drugs, the approved reimbursement price after transient compulsory reductions was considered (Table 2). The average yearly costs for the two drugs were estimated weighting the prices by the respective number of days of treatment delivered for each package available (calculated using Italian IMS Health data at July 2013 and average daily dosages reported by the PATHOS study).

COPD-related hospitalization cost was the mean diagnosis related group (DRG) reimbursement tariff derived from an Italian observational study ${ }^{15}$ and amounted to $€ 3,218$.

Average pneumonia-related hospitalization cost amounted to $€ 3,603$ and was derived from a study conducted on hospital information systems of Lazio Region, ${ }^{28}$ Italy. This was done because there is no Italian registry that can provide such information.

Table 2 Reimbursed public price per pack

\begin{tabular}{|c|c|c|}
\hline Drugs & $\begin{array}{l}\text { Reimbursed public } \\
\text { price per pack }(€)\end{array}$ & DDD \\
\hline $\begin{array}{l}\text { Budesonide/formoterol Turbuhaler }{ }^{\circledR}, \\
\text { | } 20 \text { doses } \mid 60 / 4.5 \mu \mathrm{g}\end{array}$ & 65.70 & 4 UD \\
\hline $\begin{array}{l}\text { Budesonide/formoterol Turbuhaler }{ }^{\circledast} \text {, } \\
60 \text { doses } 320 / 9 \mu \mathrm{g}\end{array}$ & 65.70 & 2 UD \\
\hline $\begin{array}{l}\text { Salmeterol/fluticasone Diskus }{ }^{\circledR}, \\
60 \text { doses } 50 / 100 \mu \mathrm{g}\end{array}$ & 41.22 & 2 UD \\
\hline $\begin{array}{l}\text { Salmeterol/fluticasone Diskus }{ }^{\circledR}, \\
60 \text { doses } 50 / 250 \mu \mathrm{g}\end{array}$ & 57.75 & 2 UD \\
\hline $\begin{array}{l}\text { Salmeterol/fluticasone Diskus }{ }^{\circledast}, \\
60 \text { doses } 50 / 50 \mu \mathrm{g}\end{array}$ & 75.59 & 2 UD \\
\hline
\end{tabular}




\section{Sensitivity analysis}

In order to support the findings of the base-case analysis, in which the most probable values of each variable were considered, we conducted different sensitivity analyses, which were designed to test the robustness of the results. Sensitivity analyses are used to determine how different values of an independent variable will impact a particular dependent variable (result) under a given set of assumptions, and are used to test the robustness of the results of a model in the presence of uncertainty and to increase understanding of the relationships between input and output variables in a model. The variables tested in the sensitivity analysis were: average drug dosages, drugs prices (considering the possible availability of generic medications), COPD-related hospitalizations cost, and pneumonia-related hospitalizations cost.

Regarding mean dosages of the two drugs, we tested the results considering the highest and lowest values for the standard deviations reported in the PATHOS study, and the defined daily doses (DDDs) reported by the WHO website ${ }^{29}$ for each formulation and strength.

For drug prices, as generic versions of the fixed-dose combination budesonide/formoterol and fluticasone/ salmeterol are expected in the near future (end of 2013 for fluticasone/salmeterol and 2014 for budesonide/formoterol) (Roggeri et al, unpublished data, 2014), we tested the current findings considering the price reduction for generic drugs indicated as convenient for the INHS (depending on the yearly expenditure of the drug) as established by Law 189 of November 8, 2012 (Decreto Balduzzi). ${ }^{30}$ In cases where the manufacturer of the generic drug accepts the price reduction indicated in the Decreto Balduzzi, the drug will be reimbursed and directly included in the "Lista di Trasparenza" (list of maximum reimbursed costs for all generic drugs); otherwise, if the manufacturer prefers a lower discount rate, a price negotiation with the health authorities is necessary. We calculated that the price reductions for which the price negotiation would not be necessary were $-70 \%$ for fluticasone/salmeterol and $-55 \%$ for budesonide/formoterol. We also tested the case of the availability of the generic drug only for fluticasone/salmeterol, to simulate the possibility of an early commercialization of this drug vs budesonide/ formoterol (this case could be realistic only for the period end 2013-2014).

In September 2013, a new fixed-dose combination of fluticasone/salmeterol with a different inhalation device (Elpenhaler $^{\circledR}$; Elpen Pharmaceutical Co. Inc., Attica, Greece) was marketed and reimbursed by the INHS in Italy - for this reason it was not considered as "generic" of fluticasone/salmeterol Diskus $^{\circledR}$; this new fixed-dose combination was considered as a reference for price for a sensitivity analysis.

For pneumonia-related hospitalizations costs, in order to evaluate the impact of the costing of this outcome on the results of the present analysis, we consider as sensitivity analysis the lowest and the highest costs reported in the Italian study conducted by Merito et $\mathrm{al}^{28}$ (corresponding to the cost associated to the age class $>85$ years and of the age class 65-74 years, respectively).

\section{Results}

The base case analysis showed that the treatment of COPD patients with budesonide/formoterol was associated with a saving in total annual cost to the INHS of $27.6 \%$ vs treatment with fluticasone/salmeterol ( $€ 1,311.60$ per patient [drugs and hospitalizations] vs $€ 1,811.50$ per patient, respectively).

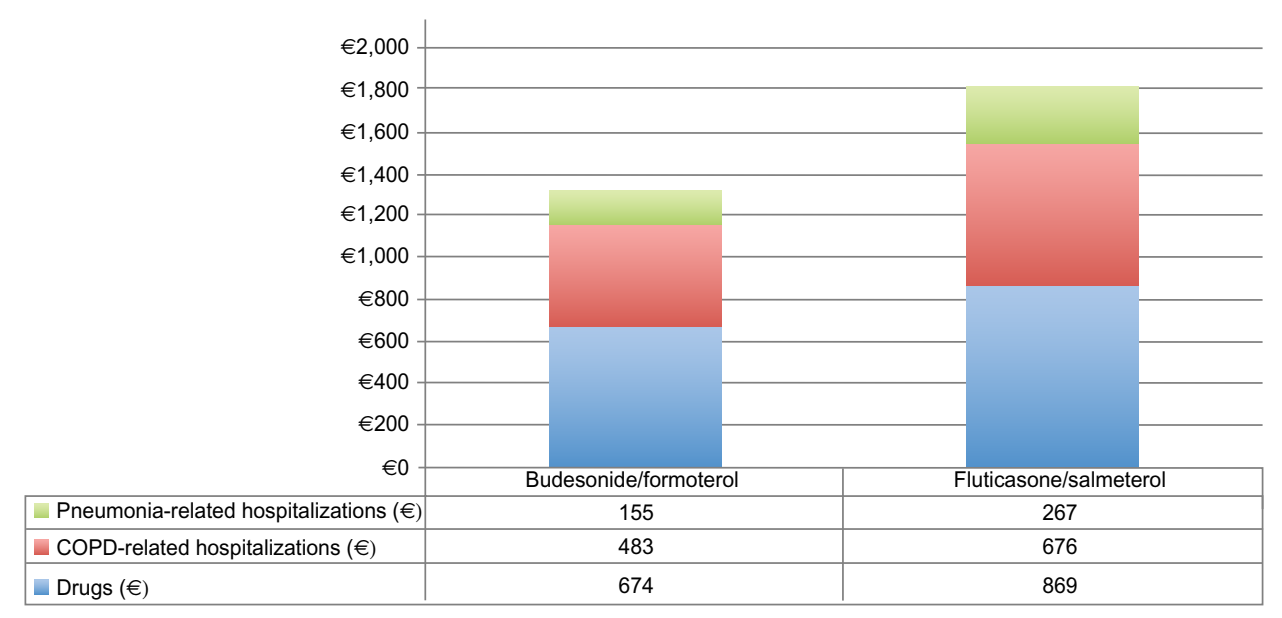

Figure I Average total cost per patient/year composition. 
Detailed results are reported in Figure 1. All cost components, in absolute values, were lower in the budesonide/formoterol group: $-€ 195.10$ per patient for drugs, $-€ 193.10$ per patient for COPD-related hospitalizations, and $-€ 111.70$ per patient for pneumonia-related hospitalizations $(-22.5 \%,-28.6 \%$, and $-41.9 \%$, respectively).

\section{Sensitivity analysis}

Several one-way sensitivity analyses were performed in order to test the robustness of the results (Table 3). All but one of these cases confirmed the economic advantages associated with treatment with budesonide/formoterol.
For all dosages considered in the sensitivity analysis, the treatment with budesonide/formoterol remained cost-saving, with a reduction per patient/year ranging from $-12.9 \%$ to $-28.1 \%$.

The availability of both generics at the prices indicated in the Decreto Balduzzi, would confirm the results of the base case analysis (-21.8\% per patient/year for budesonide/ formoterol); however, if only the generic of fluticasone/ salmeterol were to be on the market (and the price of budesonide/formoterol remains the actual price), the treatment with budesonide/formoterol would be associated with an increase in costs of $9.0 \%$.

Table 3 Sensitivity analysis results

\begin{tabular}{|c|c|c|c|c|c|}
\hline Parameter & Value & Source & $\begin{array}{l}\text { Average } \\
\text { yearly cost/ } \\
\text { patient } B / F(€)\end{array}$ & $\begin{array}{l}\text { Average } \\
\text { yearly cost/ } \\
\text { patient } F / S(€)\end{array}$ & $\begin{array}{l}\text { Difference } \\
\text { B/F vs F/S \% }\end{array}$ \\
\hline \multicolumn{6}{|l|}{ Mean drugs dosages } \\
\hline Base case & $\begin{array}{l}568 \mu \mathrm{g} \text { die B/F; } 783 \mu \mathrm{g} \\
\text { die F/S }\end{array}$ & PATHOS study ${ }^{26}$ & $1,311.60$ & $\mathrm{I}, 8 \mathrm{I} \mid \mathrm{I} .50$ & $-27.6 \%$ \\
\hline Min & $\begin{array}{l}333 \mu \mathrm{g} \text { die B/F; } 445 \mu \mathrm{g} \\
\text { die F/S }\end{array}$ & $\begin{array}{l}\text { PATHOS study dosages, }{ }^{26} \\
\text { lowest limit SD }\end{array}$ & $1,032.80$ & $1,436.30$ & $-28.1 \%$ \\
\hline Max & $\begin{array}{l}803 \mu \mathrm{g} \text { die B/F; } \\
\mathrm{I}, \mathrm{I} 2 \mathrm{I} \mu \mathrm{g} \text { die F/S }\end{array}$ & $\begin{array}{l}\text { PATHOS study dosages, }{ }^{26} \\
\text { highest limit SD }\end{array}$ & $1,590.40$ & $2,186.70$ & $-27.3 \%$ \\
\hline DDD & $\begin{array}{l}4 \text { UD for } B / F 160 \mu g, \\
2 \text { UD for } B / F 320 \mu g ; \\
2 \text { UD for } F / S^{*}\end{array}$ & WHO'29 & I,397.00 & $1,604.10$ & $-12.9 \%$ \\
\hline \multicolumn{6}{|l|}{ Drugs prices } \\
\hline Base case & $\begin{array}{l}\text { Actual public price } \\
\text { reimbursed by INHS } \\
\text { (no generics available) }\end{array}$ & $\begin{array}{l}\text { Italian reimbursement } \\
\text { price list }\end{array}$ & $1,311.60$ & $\mathrm{I}, 8 \mathrm{I} \mathrm{I} .50$ & $-27.6 \%$ \\
\hline $\begin{array}{l}\text { Reduction for generic } \\
\text { commercialization }\end{array}$ & $\begin{array}{l}\mathrm{B} / \mathrm{F} \text { actual price; } \mathrm{F} / \mathrm{S} \text { generic } \\
(-70 \% \text { vs actual price })\end{array}$ & Decreto Balduzzi ${ }^{30}$ & $1,311.60$ & $1,203.10$ & $9.0 \%$ \\
\hline \multirow[t]{3}{*}{$\begin{array}{l}\text { Reduction for generic } \\
\text { commercialization }\end{array}$} & $\begin{array}{l}\text { B/F generic ( }-55 \% \text { vs actual } \\
\text { price); } F / S \text { generic }(-70 \% \text { vs } \\
\text { actual price) }\end{array}$ & Decreto Balduzzi ${ }^{30}$ & 940.90 & $1,203.10$ & $-21.8 \%$ \\
\hline & Price of F/S Elpenhaler ${ }^{\circledR}$ & Farmadati $^{\mathrm{a}}$ & $1,311.60$ & $1,590.90$ & $-17.6 \%$ \\
\hline & Only F/S 500/50 $\mu \mathrm{g}$ dosage & Italian clinical practice & $1,311.60$ & $\mathrm{I}, 626.50$ & $-19.4 \%$ \\
\hline \multicolumn{6}{|c|}{ COPD-related hospitalization costs } \\
\hline Base case & $€ 3,218.00$ & $\begin{array}{l}\text { Lucioni et al, }{ }^{15} \text { COPD } \\
\text { hospitalization cost }\end{array}$ & $\mathrm{I}, 3 \mathrm{I} \mid \mathrm{I} .60$ & $\mathrm{I}, 8 \mathrm{I} \mid \mathrm{I} .50$ & $-27.6 \%$ \\
\hline Min & $€ 2,923.00$ & $\begin{array}{l}\text { Lucioni et al, }^{15} \\
\text { lowest limit } 95 \% \mathrm{Cl}\end{array}$ & $\mathrm{I}, 267.30$ & $\mathrm{I}, 749.60$ & $-27.6 \%$ \\
\hline Max & $€ 3,5 \mid 3.00$ & $\begin{array}{l}\text { Lucioni et al, }{ }^{15} \\
\text { highest limit } 95 \% \mathrm{Cl}\end{array}$ & $\mathrm{I}, 355.80$ & $\mathrm{I}, 873.50$ & $-27.6 \%$ \\
\hline \multicolumn{6}{|c|}{ Pneumonia-related hospitalization costs } \\
\hline Base case & $€ 3,603.00$ & $\begin{array}{l}\text { Merito et al, }{ }^{28} \text { pneumonia } \\
\text { hospitalization cost }\end{array}$ & $1,311.60$ & $\mathrm{I}, 8 \mathrm{I} \mid \mathrm{I} .50$ & $-27.6 \%$ \\
\hline Min & $€ 3,205.60$ & Merito et al, ${ }^{28}$ age class $>85$ & $1,294.50$ & $1,782.10$ & $-27.4 \%$ \\
\hline Max & $€ 3,7 \mid 7.60$ & Merito et al, ${ }^{28}$ age class $65-74$ & $1,316.50$ & $1,820.00$ & $-27.7 \%$ \\
\hline
\end{tabular}

Notes: *Mean dosages based on DDD weighted for days treatment were delivered. aFarmadati is a database containing all the administrative, legislative and commercial information about the medicines for human or veterinary use registered in Italy, equivalent medicines, homeopathic and parapharmaceutical products; available at: http:// www.farmadati.it. PATHOS study (An Investigation of the Past 10 Years Health Care for Primary Care Patients with Chronic Obstructive Pulmonary Disease; clinical trial identifier NCT0I 146392, ClinicalTrials.gov). Elpenhaler® (Elpen Pharmaceutical Co. Inc., Attica, Greece).

Abbreviations: B/F, budesonide/formoterol; $\mathrm{Cl}$, confidence interval; COPD, chronic obstructive pulmonary disease; DDD, defined daily dose; die, daily; F/S, fluticasone/ salmeterol; INHS, Italian National Health Service; Max, maximum; Min, minimum; SD, standard deviation; UD, unit dose; vs, versus; WHO. World Health Organization. 
The comparison of budesonide/formoterol with the new fixed-dose combination of fluticasone/salmeterol Elpenhaler ${ }^{\circledR}$ at the new negotiated price $(-29 \%$ vs fluticasone/salmeterol Diskus ${ }^{\circledR}$ ) suggests a savings, favoring budesonide/formoterol, of $17.6 \%$ for the INHS, confirming the robustness of the results.

By varying the pneumonia-related hospitalization costs between the highest and lowest values reported above, treatment with budesonide/formoterol vs fluticasone/salmeterol could lead to an economic saving (of $-27.4 \%$ and $-27.7 \%$, respectively).

\section{Discussion}

The current study aimed to evaluate the possible consequences of the scenario described in the PATHOS study in the Italian context. By using a specific statistical approach, we found that budesonide/formoterol combination treatment seems more advantageous than fluticasone/salmeterol combination treatment, in terms of health care cost savings, in COPD populations.

Results of the PATHOS study, in terms of reduction of COPD-related hospitalizations, emergency department visits, and medication utilization, in patients treated with budesonide/formoterol vs fluticasone/salmeterol confirmed the effectiveness data of a previous study conducted in Canada. ${ }^{31}$ This propensity-matched, Canadian COPD cohort study of 1-year duration suggested that efficacy differences may exist between the inhaled corticosteroids and longacting $\beta 2$-agonists, in favor of budesonide/formoterol. This study highlights that the budesonide/formoterol group was significantly less likely to have an emergency department visit (adjusted relative risk $[R R]=0.75$ ) or hospitalization (adjusted RR $=0.61$ ) for COPD and had fewer claims for prescriptions for tiotropium (adjusted RR $=0.71$ ).

As all clinical outcomes reported by the PATHOS study showed a higher effectiveness of the fixed-dose combination budesonide/formoterol, the present analysis could be considered conservative as only the most relevant outcomes were evaluated from the economic perspective. Moreover, results of the PATHOS study showed a significant reduction in concomitant treatment with oral steroids, antibiotics, and tiotropium in patients treated with budesonide/formoterol $(P<0.0001)$, which have not been costed in the present analysis.

The base-case analysis results were confirmed by sensitivity analysis in which all economic parameters and drugs dosages were varied between upper and lower limits in order to test the robustness of the results; the only case for which the treatment with budesonide/formoterol resulted in a slightly higher cost vs fluticasone/salmeterol was based on the availability of a generic version with a discount rate of $70 \%$ vs the actual reimbursed price of fluticasone/salmeterol Diskus $^{\circledR}$ and budesonide/formoterol - this case could be considered realistic only in the period between the patents expiration for the two drugs. The discount rates $(-70 \%$ for fluticasone/salmeterol and $-55 \%$ for budesonide/formoterol) applied in the sensitivity analysis for the two drugs were the minimum discounts, for which the generic manufacturer would not have to negotiate with health authorities in Italy; this means that manufacturers of generic versions could apply for the negotiation and obtain a lower discount rate (higher price). In this view, the hypothesis of a $70 \%$ discount for fluticasone/salmeterol and $0 \%$ for budesonide/formoterol is the most disadvantageous condition for budesonide/ formoterol; even in this case, the slight increase in costs $(+9.0 \%)$ for the treatment with budesonide/formoterol is associated with significantly better clinical outcomes in terms of mortality, hospitalization rates, and use of concomitant medications.

The major limitation of this investigation is that we used clinical outcomes from a study conducted in a real-world setting in Sweden to apply to Italian health care costs, thus assuming that the relative differences in effectiveness between the two treatments would be maintained among the two European countries.

Regardless, as described in an article published by the International Society for Pharmacoeconomics and Outcomes Research, ${ }^{32}$ there is an increasing demand from payers to demonstrate product effectiveness, not only in clinical trials but also, in a real-world setting. This need is driven by the fact that clinical trials are designed to test safety and efficacy and not to answer questions about the effectiveness of a drug in a reallife setting, which is the more relevant question for economic analysis. Internationally, real-life data are increasingly used in the development of clear, evidence-based documentation demonstrating the effectiveness value of drugs.

Observational studies offer the opportunity to recruit a more representative patient population and assess clinically relevant end points, rather than the often more short-term surrogate end points.

In the evaluation of this study limitation, it is important to consider that the PATHOS trial was one of the largest published observational studies in the respiratory area, conducted on more than 5,400 Caucasian patients. Furthermore, to our knowledge, the two treatments compared for efficacy and safety in the PATHOS study were not directly compared 
before in long-term randomized, double blind, double-dummy trials. An observational study conducted in Italy could be useful to confirm the results of the present analysis.

\section{Conclusion}

Treatment of COPD in a real-world setting with the fixeddose combination of budesonide/formoterol led to a significant improvement in relevant clinical outcomes and in a simulation, to a possible reduction in direct health care costs charged to the INHS vs the fixed-dose combination fluticasone/salmeterol. Sensitivity analysis supported the economic advantages, even once generic version of both drugs will become available.

\section{Author contributions}

All the authors participated in the conception of the study, data analysis, preparation of the manuscript, and revision of the paper and agree to be accountable for all aspects of the work.

\section{Disclosure}

AR and DPR are consultants for AstraZeneca. CM is a consultant for AstraZeneca and GlaxoSmithKline. This study was funded by an unrestricted grant from AstraZeneca, Italy. The authors report no other conflicts of interest in this work.

\section{References}

1. Global Initiative for Chronic Obstructive Lung Disease. Global Strategy for the Diagnosis, Management, and Prevention of Chronic Obstructive Pulmonary Disease. Update 2005. Vancouver, WA: Global Initiative for Chronic Obstructive Lung Disease; 2005.

2. Global Alliance Against Chronic Respiratory Diseases. Global Surveillance, Prevention and Control of Chronic Respiratory Diseases. A Comprehensive Approach. Geneva: World Health Organization; 2007. Available from http://www.who.int/gard/publications/GARD_Manual/ en/index.html. Accessed October 9, 2013.

3. Viegi G, Pedreschi M, Pistelli F, et al. Prevalence of airways obstruction in a general population: European Respiratory Society vs American Thoracic Society definition. Chest. 2000;117(5 Suppl 2):339S-345S.

4. Halbert RJ, Isonaka S, George D, Iqbal A. Interpreting COPD prevalence estimates: what is the true burden of disease? Chest. 2003;123(5):1684-1692.

5. Celli BR, Halbert RJ, Isonaka S, Schau B. Population impact of different definitions of airway obstruction. Eur Respir J. 2003;22(2): 268-273.

6. Viegi G, Matteelli G, Angino A, et al. The proportional Venn diagram of obstructive lung disease in the Italian general population. Chest. 2004;126(4):1093-1101.

7. Gibson G, Loddenkemper R, SibilleY, Lundbäck B. European Lung White Book-The First Comprehensive Survey on Respiratory Health in Europe. Huddersfield: European Respiratory Society Journals Ltd; 2003.

8. Gini R, Francesconi P, Mazzaglia G, et al. Chronic disease prevalence from Italian administrative databases in the VALORE project: a validation through comparison of population estimates with general practice databases and national survey. BMC Public Health. 2013; $13: 15$.
9. who.int [homepage on the Internet]. The top 10 causes of death. World Health Organization; 2014 [updated Jul 2013; cited October 9, 2013]. Available from: http://who.int/mediacentre/factsheets/fs310/en/index. html. Accessed April 26, 2014.

10. iss.it [homepage on the Internet]. La mortalita' per causa in Italia: 1980 2003 e 2006-2010 [The cause-specific mortality in Italy: 1980-2003 and 2006-2010]. Centro Nazionale di Epidemiologia, Sorveglianza e Promozione della Salute; 2014 [cited October 9, 2013]. Available from: http://www.iss.it/site/mortalita/Scripts/SelCause.asp. Accessed April 26, 2014.

11. Pauwels RA, Buist AS, Calverley PM, Jenkins CR, Hurd SS. GOLD Scientific Committee. Global strategy for the diagnosis, management, and prevention of chronic obstructive pulmonary disease. NHLBI/WHO Global Initiative for Chronic Obstructive Lung Disease (GOLD) Workshop summary. Am J Respir Crit Care Med. 2001;163(5):1256-1276.

12. Burney P, Suissa S, Soriano JB, et al. The pharmacoepidemiology of COPD: recent advances and methodological discussion. Eur Respir $J$ Suppl. 2003;43:1s-44s.

13. Dal Negro R, Rossi A, Cerveri I. The burden of COPD in Italy: results from the Confronting COPD survey. Respir Med. 2003;97 Suppl C: S43-S50.

14. Dal Negro R, Berto P, Tognella S, Quareni L. Global Outcomes in Lung Disease Study Group. Cost-of-illness of lung disease in the TriVeneto Region, Italy: the GOLD Study. Monaldi Arch Chest Dis. 2002;57(1):3-9.

15. Lucioni C, Donner CF, De Benedetto F, et al. I costi della broncopneumopatia cronica ostruttiva in Italia. Presentazione della prima fase dello studio ICE [Italian Costs for Exacerbations in COPD]. PharmacoEconomics - Italian Research Articles. 2004;6(1):5-14. Italian.

16. Lucioni C, Donner CF, De Benedetto F, et al. I costi della broncopneumopatia cronica ostruttiva: la fase prospettica dello Studio ICE [Italian Costs for Exacerbations in COPD]. PharmacoEconomics - Italian Research Articles. 2005;7(2):119-134. Italian.

17. Fornari C, Di Stasi F, Conti S, et al. Cost of chronic obstructive pulmonary disease: a healthcare administrative databases analysis. Value Health. 2010;13(7):A321.

18. Moretti AM, Tafuri S, Parisi D, Germinario C. Epidemiology and costs of hospital care for COPD in Puglia. Multidiscip Respir Med. 2011;6(5):299-304.

19. Giorgi Rossi P, Agabiti N, Faustini A, et al. The burden of hospitalised pneumonia in Lazio, Italy, 1997-1999. Int J Tuberc Lung Dis. 2004;8(5):528-536.

20. Dipartimento della Programmazione e dell'Ordinamento del Servizio Sanitario Nazionale Ministero della Salute. Rapporto Annuale sull'Attività di Ricovero Ospedaliero [Annual Report on Hospitalization]. Dati SDO 2011. Rome: Ministero della Salute; 2013. Available from: http://www. salute.gov.it/imgs/C_17_pubblicazioni_1930_allegato.pdf. Accessed October 9, 2013. Italian

21. Dal Negro RW, Tognella S, Tosatto R, Dionisi M, Turco P, Donner CF. Costs of chronic obstructive pulmonary disease (COPD) in Italy: the SIRIO study (social impact of respiratory integrated outcomes). Respir Med. 2008;102(1):92-101.

22. Global Initiative for Chronic Obstructive Lung Disease. Global Strategy for the Diagnosis, Management, and Prevention of Chronic Obstructive Pulmonary Disease. Update 2005. Vancouver, WA: Global Initiative for Chronic Obstructive Lung Disease; 2005. Available from: http://www. goldcopd.org/uploads/users/files/GOLDWkshp05Clean.pdf. Accessed October 9, 2013.

23. Calverley PM, Boonsawat W, Cseke Z, Zhong N, Peterson S, Olsson $\mathrm{H}$. Maintenance therapy with budesonide and formoterol in chronic obstructive pulmonary disease. Eur Respir J. 2003;22(6): 912-919.

24. Szafranski W, Cukier A, Ramirez A, et al. Efficacy and safety of budesonide/formoterol in the management of chronic obstructive pulmonary disease. Eur Respir J. 2003;21(1):74-81. 
25. Wedzicha JA, Calverley PM, Seemungal TA, Hagan G, Ansari Z, Stockley RA. INSPIRE Investigators. The prevention of chronic obstructive pulmonary disease exacerbations by salmeterol/fluticasone propionate or tiotropium bromide. Am J Respir Crit Care Med. 2008; 177(1):19-26.

26. Larsson K, Janson C, Lisspers K, et al. Combination of budesonide/ formoterol more effective than fluticasone/salmeterol in preventing exacerbations in chronic obstructive pulmonary disease: the PATHOS study. J Intern Med. 2013;273(6):584-594.

27. Janson C, Larsson K, Lisspers KH, et al. Pneumonia and pneumonia related mortality in patients with COPD treated with fixed combinations of inhaled corticosteroid and long acting $\beta 2$ agonist: observational matched cohort study (PATHOS). BMJ. 2013;346:f3306.

28. Merito M, Giorgi Rossi P, Mantovani J, Curtale F, Borgia P, Guasticchi G. Cost-effectiveness of vaccinating for invasive pneumococcal disease in the elderly in the Lazio region of Italy. Vaccine. 2007; 25(3):458-465.
29. whocc.no [homepage on the Internet]. ATC/DDD index 2014. WHO Collaborating Centre for Drug Statistics Methodology; 2014 [updated December 19, 2013; cited October 9, 2013]. Available from: http:// www.whocc.no/atc_ddd_index/.Accessed April 26, 2014.

30. Gazzetta Ufficiale della Repubblica Italiana. Il presidente della repubblica [President of the Republic]. Rome: Decreto-Legge; 2012. Available from: http://www.normattiva.it/uri-res/N2Ls?urn:nir:stato:decretolegge:2012-09-13;158. Accessed May 20, 2014. Italian.

31. Blais L, Forget A, Ramachandran S. Relative effectiveness of budesonide/formoterol and fluticasone propionate/salmeterol in a 1-year, population-based, matched cohort study of patients with chronic obstructive pulmonary disease (COPD): Effect on COPD-related exacerbations, emergency department visits and hospitalizations, medication utilization, and treatment adherence. Clin Ther. 2010;32(7):1320-1328.

32. Annemans L, Aristides M, Kubin M. Real-life data: a growing need. ISPOR Connections; 2007;13(5): 8-12. Available from: https://www. ispor.org/News/articles/Oct07/RLD.asp Accessed April 07, 2014.

\section{Publish your work in this journal}

The International Journal of COPD is an international, peer-reviewed journal of therapeutics and pharmacology focusing on concise rapid reporting of clinical studies and reviews in COPD. Special focus is given to the pathophysiological processes underlying the disease, intervention programs, patient focused education, and self management protocols.

\section{Dovepress}

This journal is indexed on PubMed Central, MedLine and CAS. The manuscript management system is completely online and includes a very quick and fair peer-review system, which is all easy to use. Visit http://www.dovepress.com/testimonials.php to read real quotes from published authors. 